\title{
Foreword \\ Special issue: Physics of Dusty Plasmas
}

\author{
K. Avinash $\dagger$ \\ Department of Physics and Astrophysics, University of Delhi, Delhi, India
}

(Received 19 May 2014)

This special issue of JPP features selected contributions from the 7th International Conference on the Physics of Dusty Plasmas (ICPDP 2014), held in New Delhi, India March 3-7, 2014.

In this conference there were 7 keynote talks, 25 invited oral talks, 15 contributory oral talks and approximately 160 poster presentations. These were in four major areas of dusty plasma physics: fundamental processes, applications, space dusty plasmas, and interdisciplinary research. The talks and poster session were arranged in eight sessions over four days.

In addition, there was a special session on the afternoon of March 7th to commemorate Padma Shukla, former Editor of JPP, who passed away on 25th January 2013 while he was visiting New Delhi to receive an award. Padma was one of the physicists who started this series of conferences in 1996. The slides of some of the invited talks (those who submitted) are posted on the conference website.

I am grateful to all contributors and anonymous referees for following the schedule of the special issue so that it could be printed in time. I am also grateful to the editorial staff of the Journal of Plasma Physics including Neil Hammond and Amanda Johns for meticulous effort in preparing this special issue of Journal of Plasma Physics. 